\title{
Eradicating Corruption in Public Service Entities through Ethical Leadership
}

\author{
By Angelo Nicolaides ${ }^{*} \&$ Tatum P. Manyama
}

\begin{abstract}
This paper investigates the need to eradicate unethical practices in the public service. It responds to high levels of corruption in the public service and explains why ethical leadership is critical to engaged ethical employee outcomes. When there is ethical leadership, the work engagement of employees is higher and they view their roles as being meaningful. The values associated with the public service need to be ethically driven and self-interest must have no place. There is no doubt whatsoever that corruption in the public sector has a hugely negative impact on a country's service delivery quality. In South Africa, despite a carefully crafted superior legislative framework and stratagems to combat corruption in the public sector, it is on the increase and invariably affects the poor the most. This is a predominantly worrying phenomenon in developing nations like South Africa where billions of dollars are required to make a success of a country. Needed resources are stolen by corrupt individuals and this means that the much needed socio-economic and developmental plans are scuppered and not achieved as planned. The apparently weak application of legislation promotes corruption and is exacerbated by a meritocratic mindset and seeming lack of political will. The public sector urgently need to lay stress on nurturing ethical leadership and motivate employees to act ethically through effective recruitment and selection, training, codes of ethics and a sense of significance in what they do at work. The oversight mechanisms also need to be carefully administered. The public service needs to nurture ethical leadership which role-models desired behaviours and stimulates employees to act ethically. An ethical stance will reduce corruption, improve the integrity of governance, public values, and also improve the societal perception of the public service.
\end{abstract}

Keywords: Accountability; Administrative responsibility; Ethical practice; Ethical leadership; Work engagement.

\section{Introduction}

Corruption is a practice which is eroding the fabric of public sector ethics globally and it threatens the sustainability of nations and the fundamentals of the global economy. This conceptual study is the result of considering that corruption in any shape or from hugely undermines the development goals of South Africa while also negatively impacting the most on the most vulnerable millions of impoverished people inhabiting the country. South Africa currently

\footnotetext{
*Professor, Graduate School of Business Leadership, University of South Africa.

Email: nicola@unisa.ac.za.

${ }^{ \pm}$Master's Student, Graduate School of Business Leadership, University of South Africa.
} 
ranks $70^{\text {th }}$ on Transparency International's latest Corruption Index ${ }^{1}$. It is an indictment on the ruling party, the African National Congress (ANC) that after a quarter of century in power, they have been unable to stop the ransacking of state resources by unscrupulous individual operating inter alia in the public service. Corruption is a world-wide problem ${ }^{2}$ which clearly undermines both the authority and the trustworthiness of the government and all its employees. What are the reasons for corruption and what challenges are faced in the fight to eliminate it as far as possible.

The paper concludes by making some recommendations and suggesting strategies on how to resolve the scourge of corruption. Cultivating ethics in any organisation, requires good role modelling by those in the upper echelons of the organisation including top management.

Since the advent of democracy in South Africa 1994, the recruitment system in the public service is open in that all posts, including promotion posts, are advertised inside and outside the public service. Selection committees are involved in the process and job specifications are set which will specify the various tasks included in a position and the skills and knowledge required. The minister of a department establishes a job description and job title that indicate:

"(a) the main objectives of the post or posts in question, (b)the inherent requirements of the job, (c)the requirements for promotion or progression to the next salary range, in accordance with a relevant career path. (Public Service Regulations, Chapter 1, Part III, Section I.1). Specific requirements for specific categories of jobs are laid down for certain occupational categories or in 'occupational specific dispensations' or for the middle and senior management service, but in many cases the discretion for setting the job specifications rests with the relevant minister. Determining job specifications, within the broad parameters set by the Minister for Public Service and Administration, has been decentralised to departments."

Once a job is advertised a selection committee is constituted and applicants are shortlisted and then interviewed. The selection committee makes recommendations on appointments to posts. The selection committee shall make a recommendation on the suitability of a candidate after careful consideration ${ }^{4}$. Subsequent to considering the recommendation of the selection committee, the minister of the relevant department, or one to whom power of appointment has been delegated, makes the appointment. Ministers or Members of the Executive Councils on provincial levels have a direct role in the appointment of DGs, other HoDs and DDGs. Candidates for posts of DG and DG are recommended by a selection panel, which comprise ministers and deputy ministers. DGs are appointed by the President with the agreement of the Cabinet while DDGs are appointed by Ministers after consensus with the Cabinet.

The authority of appointment in South Africa is allocated by section 3(7) of the Public Service Act to ministers on national level or members of the executive

\footnotetext{
${ }^{1}$ Businesstech, 22 April 2020.

${ }^{2}$ Soliman \& Cable (2011).

${ }^{3}$ Public Service Regulations - Chapter 5.

${ }^{4}$ Public Service Regulations 1/VII/D.5.
} 
council at provincial levels. Ministers are able to delegate power to officers within their departments. The justification for having this in 1994 was the necessity to transform the apartheid regime's public service. It is noted that the African National Congress (ANC) as the ruling party is under very strong criticism for their policy of cadre deployment which has also bolstered corruption ${ }^{5}$. Maladministration and the erosion of morals and also values are on the rise ${ }^{6}$. It is commonplace that municipal and other public service appointments are used to reward political cronies, which disheartens talented employees and ultimately undermines institutional performance. In such situations it is common for corruption, fraud, maladministration and mismanagement find a fertile breeding ground which very often lead to service delivery protests.

Public service training courses are unfortunately not established as a condition for permanent appointment; nevertheless compulsory initiation has been introduced for new public servants. If the public service and its National School of Government (NSG) can develop effective training courses and programmes to bridge the gap between theoretical and the practical demands of the public service, as it is done in various other countries is unclear at this stage, except to say that corruption is increasing. It is apparent from reading daily media reports that the public service is failing to place people with the right skills and competencies in the right positions.

"Generally, no specific continuous professional development requirements are set either as probation or promotion requirements. Thus, not only are there doubts about the rigour of the selection process but there are also no compulsory prescribed training courses or other compulsory development requirements that candidates must meet after appointment to address skills gaps" ${ }^{, 7}$. Such practices allow corruption to grow and structural inequalities increasingly describe and exemplify the post-apartheid South Africa. Consequently, strong anti-corruption efforts are critical in endorsing good governance and in all efforts to prevent maladministration and reduce fraud and other unethical acts. Corruption in the public sector is due to the unethical conduct of a small minority of persons but it has the potential to become a raging wildfire as people exploit the system for their own personal advantage.

The Department of Public Service and Administration (DPSA) stated ${ }^{8}$ that it will build a disciplinary database that will seek to track and monitor all government officials and public servants under investigation for fraud and corruption. DPSA minister Senzo Mchunu said that corruption and fraud investigations are the sole mandate of the South African Police Service (SAPS), while discipline management falls under the directive of the individual heads of governmental departments. Nonetheless, terms of section 15 of the Public Administration Management Act, misconduct originating from criminal investigations is a DPSA responsibility. Thus he said "It is therefore envisaged that the newly established Public Administration Ethics, Integrity and Disciplinary Technical Assistance Unit will

\footnotetext{
${ }^{5}$ Ruhiiga (2009); Areff (2012).

${ }^{6}$ De Waal (2012).

${ }^{7}$ Public Service Regulations - Chapter 5.

${ }^{8}$ Businesstech, 22 April 2020.
} 
establish a central disciplinary database to monitor, track and record public servants under investigation for misconduct which may include corruption and fraud".

\section{The Role of Ethical Leadership}

Corruption has developed into a leading topic of discussion amongst the public and it is ever-present in the popular media and in civil society organisations as well as the private sector ${ }^{10}$.

Hassan, Wright and Yukl ${ }^{11}$ explored a study on various aspects including ethical leadership, willingness of the employees to report ethical problems, organisational commitment and absenteeism of public sector employees. The study employed a survey research by means of questionnaires. The study showed that there is a positive relationship between all dimensions, an increase in reporting ethical problems that arises to management, commitment to the organisation and reduction in occurrences of absenteeism by employees of the public sector. This informs that ethical leadership plays an important role in an organisation.

Ethical leadership has three components that are essential, a role model that is ethical to others, fair treatment of people and management of ethics within the organisation actively. Leaders that have ethics take cognisance of moral implications when choices are made. In some cases absenteeism is not caused by employees who are ill or family emergencies. Ill-treatment, stress or a decline in morale at a workplace causes some form of absenteeism due to an employee's refusing to be compromising personal values and work ethics. When an environment is conducive ${ }^{12}$, it is not only about implementing ethical standards or codes. When an organisation has ethical leaders, that is leaders whose behaviour is supportive and procedures that are fair, this can create an organisational climate that is safe for employees to be able to feel comfortable in addressing and reporting ethical problems ${ }^{13}$. Reporting of any behaviour that is not ethical will have a positive impact in the organisation and discourages the continuance of unethical behaviour due to the confidence employees have in the leadership of the organisation's ability to appropriately take corrective action when required. The success of an ethical environment and compliance of ethical standards or codes is dependent on the leaders of the organisation ${ }^{14}$.

It is of critical importance to promote ethical behaviour by managers in the public sector organisations and reduce unethical practices. This is realised by implementing guidelines and ethical standards that are set out clearly. Employees should be part of the process and be provided with an opportunity to seek advice

\footnotetext{
${ }^{9}$ Businessstech, 22 April 2020.

${ }^{10}$ De Graaf (2007).

${ }^{11}$ Hassan, Wright \& Yukl (2014).

${ }^{12}$ Hassan, Wright \& Yukl (2014); Nicolaides (2019).

${ }^{13}$ Nicolaides (2013); Nicolaides \& Duho (2019).

${ }^{14}$ Nicolaides (2009); Nicolaides (2014); Nicolaides (2016); Nicolaides (2017); Nicolaides \& Duho (2019); Hassan, Wright \& Yukl (2014).
} 
on dealing with ethical matters ${ }^{15}$. Ethical training affords a chance for employees to know and understand what is ethical and how to deal with ethical dilemmas. Good ethical leadership is equally important and development programs in leadership must include awareness in ethics, influence of employees attitude and behaviour by creating trust relationships and good ethical behaviour modelling.

Cohen \& Eimicke, D'Aleo, Lokman \& Talib, Nicolaides and Plant ${ }^{16}$ provided an overview and the analysis of practical problems that are encountered when codes of ethics are developed and implemented. The dimensions that were explored are

1. What are public ethics and where do they come from?

2. What are the central ethical issues facing public administrators?

3. Are there practical tools and guidelines to assist public servants to be both ethical and effective public managers?

The articles indicate in varying degrees how public ethics differs in relation to personal ethics because of values and guiding principles. It suggests that public ethics does not only consider right and wrong or action and performance when making judgements, rather it looks at action-based judgements. However, public administrators must be guided on how to be able to make those judgements. This is encouraged through concepts such as responsibility, professional lenses, a good perspective of humanity in general, values, agency goals and personal view. In an African context this would be very much in line with the notion of Ubuntu ${ }^{17}$. Ubuntu should inform practice in African business. Ubuntu is an African communitarian philosophy which should be used to transform management practices in the public and private sectors in African nations. The relationship between society and business must invariably be viewed from an Afro-centric perspective. Consequently, the indigenous phenomenon of Ubuntu should be informing business activities such as the codes of ethics that are created to maintain a 'moral compass' in organisational activities. This will hopefully improve the current situation in the public service sector where there is scant attention paid to seriously serving others ${ }^{18}$.

Cohen \& Eimicke, D'Aleo, Lokman \& Talib, Nicolaides, and Plant ${ }^{19}$ show a different view in terms of development and implementation of codes of ethics. It revealed that public administrators do not have a problem with following what the guidelines of regulations stipulate, however, when there are no legal guidelines that are clear, the public administrators experience a problem in dealing with situations that are perceived to be complex. D'Aleo ${ }^{20}$ and Nicolaides ${ }^{21}$ say that codes of ethics or standards may be developed, however, it important to ensure

\footnotetext{
${ }^{15}$ Hassan, Wright \& Yukl (2014).

${ }^{16}$ Cohen \& Eimicke (1995); D'Aleo (2018); Lokman \& Talib (2016); Nicolaides (2009); Nicolaides (2014); Nicolaides (2017); Plant (2018).

${ }^{17}$ Nicolaides (2014).

${ }^{18}$ Nicolaides (2014).

${ }^{19}$ Cohen \& Eimicke (1995), D'Aleo (2018), Lokman \& Talib (2016), Nicolaides (2009), Nicolaides (2014), Nicolaides (2017), Plant (2018)

${ }^{20}$ D'Aleo (2018).

${ }^{21}$ Nicolaides (2019).
} 
that they are implemented and are enforced by some form of prescripts. Furthermore, for those who violate ethical practices there should be consequences. Unethical behaviour is detrimental as it can affect the community, foreign investment and destabilise the reliability of public institutions. In the same breath for those employees who display positive behaviour over and above the call of duty, there must be a reward, recognizing good ethical behaviour. Cohen and Eimicke $^{22}$ and Nicolaides ${ }^{23}$ state that training is another important dimension in encouraging behaviour that is of a high moral nature. Furthermore, the leaders of an organisation are important in ensuring that ethical practices persist irrespective of the nature of the environment. When the leadership is not acting as a role model, this tends to make the employees steer away from complying with the necessary standards that have been implemented to deal with ethics ${ }^{24}$. It is not difficult for the public service to distinguish right from wrong. Role models and reward systems that are appropriate enable ethical behaviour. The dilemma lies where public servants are prevented from executing their duties in the right manner due to obstacles such as lack of training on ethical aspects of work. Ultimately it is the responsibility of each public servant that is assigned a task to decide which tasks he or she is willing to execute ${ }^{25}$ even though the tasks are provided by superiors. To maintain good ethical practices in the public service requires one with steadfast moral principles in both the personal and professional spaces.

According to Mansouri ${ }^{26}$ the Volkswagen scandal that unfolded in 2015 was due to the installation of "defeat devices" in order to comply with the United States new set of stringent regulations on emissions. It was revealed that a number of employees from managerial to non-managerial to the rank and file workforce, were part of the employees who played a role in the execution of the unethical action that occurred. The culture of Volkswagen's environment was that of avoiding discussions and dissent with management at all costs.

Prior to the scandal, Volkswagen was praised as one of the organisations that has an outstanding ethical business approach and received an 'Ethics in Business Award. However, with the implementation of stringent new requirements on emission and the inability to initially comply by the date set by Volkswagen, made Volkswagen vulnerable and they then resorted to committing an act that is unethical. Volkswagen's culture is known to be autocratic rather than democratic. $^{27}$ The culture of an organisation affects the level of compliance with ethical codes or standards ${ }^{28}$. When an organisational environment is such that employees are not free to express their own opinion or be involved in decisionmaking processes, it results in them acting in a manner that is not ethical to meet the organisations goals. This shows how organisations that are well established

\footnotetext{
${ }^{22}$ Cohen \& Eimicke (1995).

${ }^{23}$ Nicolaides (2016).

${ }^{24}$ Nicolaides (2009).

${ }^{25}$ Plant (2018).

${ }^{26}$ Mansouei (2016).

${ }^{27}$ Aurand, Finley, Krishnan, Sullivanm, Abresch, Bowen, Bowen, Rackauskas, Thomas \& Willkomm (2018).

${ }^{28}$ Nicolaides (2016) 'Nicolaides (2017) ; Nicolaides (2019).
} 
can falter from conducting ethical to unethical business practices to advance sales. The success of codes of ethics requires a combination of ethical leadership, training to enhance moral behaviour ${ }^{29}$. A democratic environment where every employee is able to freely express and discuss any matter pertaining to the organisation is also crucial ${ }^{30}$. Ethical business practices apply both in the public and the private sectors. This is despite the fact that he public sector is generally not about profit again whereas the private sector is. The public sector still suffers immense organisational losses through unethical conduct and corruption.

Sayeed ${ }^{31}$ conducted a study that revealed that ethical values of public officials have an impact on accountability and that the ability of public officials to perform their duties is guided by moral values principles and rules. The study defines "public service ethos" as set of values that are meant to provide guidance and motivation for public servants while practicing their profession". An organisation's ethics and value system must stem from the leaders in the organisation ${ }^{32}$. It also reinforces the fact that an organisations main goal is to create a common identity to establish codes of conduct. The leaders in the organisation are critical in ensuring that standards and professionalism is maintained. In any event, the Constitution of the Republic of South Africa 1996 prescribes the rudimentary principles that are required to serve as guiding tools for public functionaries in executing their duties. Public servants are to promote and maintain a high standard of professional ethics must be prioritised (Section 195 of the Constitution of the Republic of South Africa, 1996). Codes of conduct, ethos in the public service and training programmes are tools that should be considered in finding solutions ${ }^{33}$. Further, Sayeed ${ }^{34}$ notes that integrity training is one other element that was identified as being important and must be incorporated to form part of the programmes. This will assist in raising moral awareness, reasoning and quality pertaining to actions that needs to be taken.

The Constitution has established what is denoted to as Chapter nine (9) institutions including the Offices of the Public Protector and the Auditor General (AG). Their determination is to promote democracy by protecting the public sector against unethical and corrupt practices. In addition, the South African public sector, civil society groups and business launched a concerted effort in 2011 to establish a National Anti-Corruption Forum (NACF) to combat growing corruption. While some efforts are being made corruption is increasing. Corruption and inefficient government bureaucracy are substantial dangers in the public services sector. It is not uncommon for irregular payments and bribes to be frequently exchanged and nepotism and cronyism are also very common problems to deal with while corruption in public procurement is a high risk for businesses operating in South Africa (South Africa Corruption Report, May 2019). Preferential treatment in the decisions of government officials is apparently very

\footnotetext{
${ }^{29}$ Nicolaides (2019).

${ }^{30}$ Mansouri (2016).

${ }^{31}$ Sayeed (2016).

${ }^{32}$ Nicolaides (2017).

${ }^{33}$ Nicolaides and Duho (2019).

${ }^{34}$ Sayeed (2016).
} 
common, and public funds are frequently diverted due to corruption ${ }^{35}$.The BroadBased Black Economic Empowerment (BBBEE) strategy seeks to grow the involvement of black citizens in the economy but has been criticised both for providing too much privileged treatment in the awarding of government contracts to wealthy black elites and for promoting increased corruption in public procurement and there is also a lack of monitoring and assessment, maladministration, difficulties in registering companies under BBBEE, and poor accountability ${ }^{36}$.

South Africa, despite its good legal framework for curbing corruption, still has disturbingly growing corruption levels. Laws such as The Prevention and Combating of Corruption Act 12 of 2004 (PCCA) criminalise corruption in public and private sectors and codify specific offenses. This was intended to make it easier for courts to prosecute corrupt crimes. The Act explicitly criminalises corruption, extortion, active and passive bribery, bribing a foreign official, abuse of office and money laundering, and it obliges public officials to report corrupt activities (South African Government, 2004). In addition, The Public Finance Management Act 29 of 1999, addresses unauthorised government expenditure and there are also numerous other legislations of note but the problem of corruption remains ${ }^{37}$.

South Africa has sanctioned the United Nations Convention against Corruption, as well as the African Union Convention on Preventing and Combating Corruption and the OECD Anti-Bribery Convention but corruption keeps growing.

Good moral values allow one to make decisions without difficulty and be able to perform set out activities with integrity. Employees require to be held accountable for the decisions that are taken in the process of executing activities. Implementation of codes of conduct is not sufficient, enforcement influences good ethical behaviour to strive ${ }^{38}$. An additional view that is shown in the study is that there has to be a division that is responsible for overseeing ethical standards in an organisation. This is a unit that has the responsibility to ensure all the rules and guidelines are adhered to. The unit has to have a strong arm and action be taken for those who violate behaviour that threatens the climate of the organisation. Furthermore, introduce reward compliance for employees that execute and behaviour ethically in all aspects of their duties.

Krisnajaya ${ }^{39}$ investigated the "Institutionalisation of ethical principles to overcome ethical dilemma in the Public Sector". In the study it became apparent that personal virtue and public virtue inconsistencies contribute to public sector's ethical problems. The ability to be able to distinguish right or wrong alleviates the dilemma of making the right decisions. Public sector ethics are about stringent adherence to protocols, rules and organisational procedures. In the public sector there tend to be dilemmas that are often caused by politics as power is

\footnotetext{
${ }^{35} \mathrm{GCR}$.

${ }^{36}$ Shava (2016).

${ }^{37}$ Treasury.gov.za (1999).

${ }^{38}$ Cohen \& Eimicke (1995); D'Aleo (2018); Krisnajaya (2018); Nicolaides (2019).

${ }^{39}$ Krisnajaya (2018)
} 
overly exercised in some instances ${ }^{40}$. These are in contradiction with the ethics principles that should be observed in the organisation. The study also revealed that a leader must be someone that the employees will look up to and must have strong ethical principles as this will assist the organisation in accelerating the establishment of ethical principles in the organisation ${ }^{41}$. The implementation of institutionalisation of ethical codes or standards should be followed with effective enforcement and the institution of consequences for non-compliance in order to minimise the risk of unethical behaviour. For the improvement of ethical conduct, ethical codes must not ambiguous but clear, and within the legal framework, system for accountability in the public service, and there should be transparency and accountability in the decision-making processes. Employees must act ethically and show ethical behaviour at all times, and there must be adequate consequences for transgressors ${ }^{42}$.

Wright, Hassan and Park ${ }^{43}$ conducted a study to investigate whether the public service ethic encourages ethical behaviour, public service motivation, ethical leadership and the willingness to report ethical problems. It was discovered that there is a positive relationship in all the dimensions that were investigated, that is, public service managers with a high public service motivation (PSM) show greater ethical leadership than managers with low PSM. Those leaders will have subordinates who have a higher PSM and are willing to report any violations of ethical behaviour observed in the organisation, and often do so as whistleblowers.

\section{Role Modelling desired Behaviour}

Leaders who encompass ethical values are expected not only to conduct themselves as to bring awareness through communication and enforcement of ethical behaviour, but also through their actions. Monitoring of employees and ethical training has been associated with codes of practice adherence, reduction in violations, in appropriate use of sick leave and an increase in reporting of ethical violations. Employees observe what happens in their organisation and if the organisation affords rewards to those employees who show an ethical behaviour, and sanctions violations of ethical conduct, this will separate those employees have strong moral and professional values ${ }^{44}$. Those with strong ethical values will tend to model their behaviour around that of their leader and the opposite applies for those who do not have strong values. Employees are often also faced with the dilemma in an organisation due to the environment that deprives them of a sense of freedom to express themselves. Employees in some cases resign or are consistently absent from work because of such conditions. When leaders show their subordinates that there is consistency of fairness in dealing with ethical and unethical behaviour, employees will be encouraged to remain in the organisation.

\footnotetext{
${ }^{40}$ Nicolaides (2019).

${ }^{41}$ Krisnajaya (2018).

${ }^{42}$ Nicolaides (2009).

${ }^{43}$ Wright, Hassan \& Park (2016)

${ }^{44}$ Wright, Hassan \& Park (2016).
} 
Yeboah-Assiamah, Asamoah, Bawole and Buabeng ${ }^{45}$ studied leadership and ethics in the public sector subordinates. The study revealed that subordinates emulate the behaviour that is shown by their leaders. When leaders in an organisation display a behaviour that is unethical, the subordinates will not uphold good ethics. In some cases the subordinates will take the blame for the unethical behaviour because of the relationship between the individuals and the supervisor, or even perhaps because of fear of retaliation from the supervisor if the unethical action(s) is not carried out.

This study sought to establish whether public service managers with public service motivation (PSM) that is high, exhibit leadership that is more ethical than those with low public service motivation. Managers with high public service motivation, subordinates will have high public service motivation and that employees with high public service motivation have the willingness to report unethical behaviour when observed in the organisation. The study revealed that there is a positive link between public service motivation of the supervisor and leadership that is ethical. Subordinates with a high PSM are willing to report any unethical conduct to their superiors ${ }^{46}$.

Unethical behaviour that is in the organisation sometimes flows into the field of work. For instance, where there are allegations of public servants who are responsible for conducting roadside inspection, committing acts of unethical behaviour in the process of executing their responsibilities the supervisors are aware and may even support such behaviour. They may even expect the officials to return with 'sales' although the responsibilities of officials do not include 'sales'. This involves unethical behaviour by collecting money when for example, conducting roadside inspections. When a leader does not display a behaviour that is ethical, subordinates will emulate that behaviour, hence, the behaviour will persist to exist as management is permitting it to endure by not reprimanding unethical conduct. The decay of an organisations moral system from topmanagement makes policies that are implemented ineffective and the leaders that are supposed to be role models are not setting good example to the subordinates to whom they are responsible ${ }^{47}$.

When top-management embraces ethical behaviour, it will probably tend to cascade down to the rest of the organisation, and when an organisation embraces unethical behaviour, it will affect the whole organisation negatively and lead to its non-sustainability. Yeboah-Assiamah, Asamoah, Bawole and Buabeng ${ }^{48}$ state that organisational recruitment processes need to be expanded to include mechanisms that will assist in making sure that candidates that are recruited are indeed ethical and moral individuals. Training must be part of the process in the organisation to provide all employees with knowledge about unethical conduct and the negative consequences thereof. Although there are supervisors, individuals need to be aware of consequences of unethical behaviour conduct. Any individual is not exonerated for unethical behaviour because of their supervisor's being aware of it

\footnotetext{
${ }^{45}$ Yeboah-Assiamah, Asamoah, Bawole \& Buabeng (2016).

${ }^{46}$ Wright, Hassan \& Park (2016).

${ }^{47}$ Nicolaides (2016).

${ }^{48}$ Yeboah-Assiamah, Asamoah, Bawole \& Buabeng (2016)
} 
or even their part in unethical conduct. Consequences must be severing for all those who conduct unethical behaviour. In most cases top-management do not experience any adverse consequences due to their connection within the organisation and with their political cronies. In the public service, the middle management are mostly the individuals that are found guilty of sever malpractice and unethical conduct.

Nkyabonaki $^{49}$ explored the level of awareness of codes of ethics in the public service, contribution of the codes to deal with corruption and, ethics promotion and the level of incentives. There was no positive relationship on all the dimensions that were investigated. Evidence in the study reveals that the employees are not familiar with the contents of the codes of ethics, which renders the level of awareness inefficient. The implementation of the code of ethics did not yield positive a result because of the existence of behaviour that is corrupt induces the codes of ethics to be ineffective. On the level of incentive dimension, it was not found that there is a positive relationship. Underpayment demotivates public servants in the execution of their duties and responsibilities to serve in a manner that is diligent and impartial, and therefore codes of ethics are not adhered to as they should be and this is a problem in the African context ${ }^{50}$.

\section{Codes of Practice}

The study states that ethics is about what is right or wrong, what is considered acceptable and not acceptable and the connection with the peoples value systems. Codes of practice outline the level between right and wrong in the public sector for the employees. This is the basis for the level of professionalism required for the public sector and promotion of principles of good governance and efficiency. Codes of practice will be rendered useless if there is lack of internal mechanisms that will support and promote the code. Leaders in the organisation needs to be role models and lead by example as this will likely promote positive behaviour by employees as they emulate what leaders do.

The public sector is divided into two levels, that is, the political and administrative level, where policy formulation and core decisions are taken; and then there is the implementation of policies and decisions respectively. These levels pose a challenge when synergy does not exist in terms of codes of practice, as in some cases, the political level will insist on activities that are not in line with the requirements of the codes of practice, however, the employee is instructed to carry out activities. Responsibility, transparency, non-existence of conflict of interest and efficiency are some of the virtues $\mathrm{Nkyabonaki}^{51}$ believes ethics must be based on. The problem occurs when employees has conflict between private and professional work ethics or the culture of the organisation. Each individual needs to be held accountable for every action that is taken by them in the process

\footnotetext{
${ }^{49}$ Nkyabonaki (2019)

${ }^{50}$ Nicolaides (2014).

${ }^{51}$ Nkyabonaki (2019)
} 
of performing work activities. Nkyabonaki ${ }^{52}$ just like other researchers stresses the point of enforcement and an appropriate sanction for violators. It is believed that the political will for adherence to codes of practice and commitment thereof could be able to enhance compliance, through training and bureaucratic ethics.

Dodek's article ${ }^{53}$ explored the future of ethics in the public sector. The study suggests that there are many challenges that are faced by accountability or ethics officers. What was found is that the accountability officers require strengthening due to political accountability failure. This means that individuals that exercise power through a political process should be held accountable for their actions. The ineffectiveness of legislature to discipline their members gave rise to accountability offices. The development of a framework is important, as it will provide proper guidance, consistency and fairness in matters relating to ethics, rules and regulations ${ }^{54}$. Accountability officers are required to have a dual role in performing advisory and enforcement functions instead of a mere unitary model. This will ensure effective and objective execution of functions. The study suggests that to improve ethical behaviour the toolkit used needs to include various levels. In dealing with ethics contravention, different and continuous mechanism needs to be developed to address the ethics regime. Sanctions for non-compliance need to be strengthened to deter political level and administration level from conducting unethical behaviour such as escalating penalties for those who continually offend and complex contraventions steep/serious penalties must be instituted. The system for accountability officers in the public sector needs overhaul and turn it into an active system and deal with promotion of ethical behaviour and not merely with deterring and punishing ethical misconduct.

According to Nicolaides ${ }^{55}$, South Africa's basis for promotion of ethical conduct is prescribed in the Constitution. In 1997 the Public Service Commission commenced its role to promote a code of conduct. This was meant for national, provincial and municipalities public servants. All public servants are thus required to place their public interest ahead of their own and to act and behave in an ethical manner while executing their responsibilities. An organisational climate that is ethical is influenced by leadership that has a strong moral system in place. It is stated that South Africa instituted a process that will drive a culture that is ethically strong in order to allow the reduction of unethical conduct and eliminate the perception that the public service is unable to provide a moral and competent government. When a leader is a role model and has a good moral compass, people that are under his or her leadership will tend to follow suit ${ }^{56}$.

There were various pieces of legislation that were implemented to promote values of accountability and transparency. Ethical frameworks also need to be established that will encompass policies, procedures and internal controls that are appropriate $^{57}$. All public servants should be provided with training which will

\footnotetext{
${ }^{52}$ Nkyabonaki (2019)

${ }^{53}$ Dodek (2018).

${ }^{54}$ Dodek (2018).

${ }^{55}$ Nicolaides (2016).

${ }^{56}$ Nicolaides (2016).

${ }^{57}$ Nicolaides (2016).
} 
impart information and the understanding of ethical issues in the organisation and how to they should be dealt with ${ }^{58}$. Public servants activities whether ethical or unethical have an impact on the country's business environment and public support for local initiatives ${ }^{59}$. The Public Service needs to invest in ethics education and governance for future generations to install the concept of doing what is right by providing knowledge on relevant ethical matters. The office Auditor General (AG) in its reports for 2010 to 2013 considered corruption to be a two way process that comprises both public and the private sector role-players, who together engage in illegitimate and unethical actions that reduce South Africa's economic prospects and break down the public service. Society then also requires greater education on the issue of doing what is right.

Wright, Hassan \& Park $^{60}$ argue that ethical climate must be driven from the top management, with implementation of rewards system for ethical behaviour, and clear decision-making processes including a dimension of ethical value. Appropriate internal structures thus need to be implemented to oversee development of codes and their implementation, monitoring, enforcement, training provisions, regular educational and awareness on ethical matters ${ }^{61}$. For transgressions of any unethical conduct, there should be consequences for all involved. For an institution to succeed in its ethical journey, it needs an ethical culture that is strong and fully supported strongly by the leaders in the institution.

\section{The Need for Effective Employee Induction and Training}

Sebola $^{62}$ investigated ethical problems in the public service and training that is provided to students who are studying public administration. The study showed that the training that is provided to the students does not prepare the student adequately for the realities within the public service. Furthermore, the study suggests that politicians in public administration need to be made to respect rule of law and they must be held accountable for any unethical behaviour. The duty of politicians and public servants is to serve the interests of the people. Politicians and senior managers' are mostly implicated in not adhering to ethical codes, although these are the people who implement mechanisms to deal with unethical behaviour ${ }^{63}$. The constitutional principle requires that standards of professionalism and ethics be maintained and promoted at all times for operations in all government institutions and thus whatever is done must be done on ethical and moral grounds and this includes all municipalities and public entities. There are many laws that have been put in place, however, unethical behaviour still persists $^{64}$. Despite a National Anti-Corruption hotline being created for

\footnotetext{
${ }^{58}$ Mafunisa (2007).

${ }^{59}$ Nicolaides (2016).

${ }^{60}$ Wright, Hassan \& Park (2016).

${ }^{61}$ Sebola (2018) and Sayeed (2016).

${ }^{62}$ Sebola (2018).

${ }^{63}$ Sebola (2018).

${ }^{64}$ Mle \& Maclean, 2011; Manyaka \& Sebola (2013).
} 
whistleblowers as a means to increase access to report wrong doing corruption in the South African public sector remains a foremost challenge ${ }^{65}$.

Nicolaides and Duho ${ }^{66}$ indicated that training is a solution to ethical problems, although, it seems that training has already been undertaken. There are positive results in inducing ethical behaviour ${ }^{67}$ such as implementing strong anti-corruption capabilities in all public service departments and more effective use of the Prevention and Combating of Corrupt Activities Act, Act No. 12 of 2004.

The current President of South Africa, Cyril Ramaphosa, has undertaken to take action against corruption and has referred to the period under former president Jacob Zuma as "the lost decade", and a period marred by corruption allegations, nepotism, and 'state capture ${ }^{68}$. The president on Monday stated on 20 January that "We are committed to end the practice of poorly qualified individuals being parachuted into positions of authority through political patronage. There should be consequences for all those in the public service who do not do their work" ${ }^{\text {" }}$. The proof of the pudding is in the eating thereof.

Perhaps what are needed are mechanisms and measures to have more effective training, and awareness workshops on an on-going basis so that gaps that still exists can be identified and mitigated.

The question is if the Service Commission has been mandated to ensure that professionalism and ethics of high standards are maintained and promoted by means of codes of ethics and guidelines, and through conducting of ethical workshops and training for both the national and provincial public servants. Is there recourse by the Service Commission for those public servants who have been implicated in an unethical conduct? This fact is not mentioned in the study. Sebola ${ }^{70}$ states that the Service Commission role was that of a recommendatory function. The role of the Commission should be made that of an enforceable one to be able to deal with compliance of ethics in a more effective way. There are many politicians that have been implicated in unethical behaviour as well as managers. It is however mainly politicians who seems to be operating outside of the law in the process of implementing principles of public administration.

Ethical practices are important and standards have to be developed and implemented so that there is a guideline that gives direction to an organisation, its leaders and employees. There are similar commonalities and themes in all the literature that was reviewed. All the dimensions: ethical leadership, willingness of the employees to report ethical problems, organisational commitment and absenteeism of public sector employees; an overview and the analysis of practical problems that are encountered when codes of ethics are developed and implemented; further dimensions were explored. Questions included (1) what are public ethics and where do they come from? (2) What are the central ethical issues facing public administrators? And (3) Are there practical tools and guidelines to

\footnotetext{
${ }^{65}$ Manyaka \& Sebola (2013).

${ }^{66}$ Nicolaides \& Duho (2019).

${ }^{67}$ Nicolaides (2014), Nicolaides (2016) and Nicolaides (2017).

${ }^{68}$ Businesstech (January 2020).

${ }^{69}$ Businesstech (January 2020).

${ }^{70}$ Sebola (2018).
} 
assist public servants to be both ethical and effective public managers, such as the installation of unethical conduct defeat devices or the institutionalisation of ethical principles to overcome ethical dilemmas in the Public Sector; Does the public service ethic encourage ethical behaviour, public service motivation, ethical leadership and the willingness to report ethical problems? Is leadership in the public sector showing good awareness of codes of ethics and their value in the public service, and does the contribution of the codes help deal with corruption and the promotion of ethics? Are incentives dealt with? The future of ethics in the public sector is very important and has a huge influence on how a nation is viewed. . An organisation needs structures to support an ethical climate. The implementation of law or codes alone is not enough to address unethical behaviour. This need to be reinforced by attending courses on ethical conduct as training has been found to stimulate moral behaviour in employees ${ }^{71}$.

It is the responsibility of public employees to make sound moral judgements and demonstrate sound personal value in terms of the type of activities that they will perform. It is not easy to be a public administrator and at times personal values might be compromised due to the pressure of the environment. This is often caused by the threat of retaliation by unscrupulous parties. Employees with strong personal values face the prospect of being treated in an unfair manner by corrupt individuals with whom they work.. What is also of importance is to implement guidelines for consequences for those who contravene ethical standards or codes ${ }^{72}$. An organisation has to implement or appoint ethical agents to be the drivers of ethics initiatives and deal with issues of education and awareness. Leadership that is of an ethical nature has a positive impact on the ethical climate and therefore leaders must conduct themselves in a way that is exemplary and will encourage ethical behaviour and enhance desired ethical compliance amongst all employees ${ }^{73}$.

Organisations are obligated to maintain the work environment conducive for personnel to report any illegal activities without being threatened or feel victimised by senior management or any superior. They also have an obligation to keep the environment safe in order to protect the community and their reputation from being tainted on media. Therefore, it is vital for the organisation to have systems in place that adhere to laws, regulations, standards, polices etc. that are effective in ensuring that all employees are aware of what is expected and the steps to take in accordance with anticorruption notions. Organisations must develop strategies to decrease the risk of illegal activities that might affect the business and environment by building a culture of ethical leadership, encouraging reliability and providing good business ethics due to the fact that ethical leadership promotes openness and safe communication. Ethical leadership eliminates the chances that an ethical dilemma that may occur which often leads to a manager to facing very difficult challenges that involve possible loss or gain or undeserved benefit which must be avoided in a business seeking to keep its reputation intact.

\footnotetext{
${ }^{71}$ Sayeed (2016).

${ }^{72}$ Krisnajaya (2018).

${ }^{73}$ Krisnajaya (2018).
} 


\section{Strategies to consider in efforts to Eliminate Unethical Conduct}

There are strategies that are considered to be effective in improving ethics in an organisation that is under top management (moral management): board of directors, ethics programs, officer's realistic objectives, effective communication, training in ethics, corporate transparency, reporting mechanisms, and discipline of unethical conduct and codes of conducts.

\section{a. Codes of conduct}

It is arguable that a Code of Ethics is the most important document in the organisation. It forms an integral part of the ethics and compliance program ${ }^{74}$. Top management has to obtain the buy-in from all to make sure that the standards pertaining to behaviour are established and that the standards are communicated to all employees in the organisation and that this includes all managers. The purpose of the code is to provide direction as well as the meaning as to what exactly is meant by ethical business conduct.

Ethical behaviour may be influenced by the codes of conduct through metaphors that are viewed by the employees in the organisation or they may even be perceived as a rule book, signpost, mirror, magnifying glass, shield, smoke detector, fire alarm or even a club that employees belong to.

\section{b. Organisational culture}

Naidoo $^{75}$ maintains that the culture of the organisation involves values that are shared, and also the beliefs, behaviours and the way in which things are done. For an organisation to improve its ethical culture, the strategies thereof must come from all the levels of management within the organisation matrix ${ }^{76}$. The success and sustainability of business ethics is dependent on the support from top management including the board of directors and all employees must be involved $^{77}$.

\section{c. Reporting mechanisms}

Hassan, Wright and $\mathrm{Yukl}^{78}$ suggest that proper mechanisms should be implemented for employees to able to know what to do should they witness unethical behaviour taking place. Reporting on such behaviour is dependent on those mechanisms such as support from the leaders and hotlines that may be available $^{79}$. However, the organisation has to properly investigate the accusations

\footnotetext{
${ }^{74}$ Nicolaides (2016).

${ }^{75}$ Naidoo (2016).

${ }^{76}$ Nicolaides \& Duho (2019).

${ }^{77}$ Mansouri (2016).

${ }^{78}$ Hassan, Wright \& Yukl (2014)

${ }^{79}$ Wright, Hassan \& Park (2016).
} 
first in order to establish the truth before commencing on the process of taking action against the wrongdoer. Anonymity is important when it comes to reporting behaviours that are not acceptable because the person reporting will not be afraid of being victimised, as their identity will not be known.

\section{d. Training in ethics}

Hassan, Wright and $\mathrm{Yukl}^{80}$ posit training goals for ethics must include learning about basics for business ethics, solving problems in ethics, ascertaining what causes unethical behaviour, what are common ethical managerial issues, how to report unethical behaviour and what are the risks of reporting, the development of the ethics code and how an ethical audit may be conducted within the organisation $^{81}$. It is recommended that for ethics training to be effective, trainees should be exposed to a programme that has a lengthy duration to realise the improvements in the employee's moral development. All members of the organisation should be subjected to on-going training from the Minister in the public service or the CEO in the private sector, all the way down to the lower level so that the whole organisation is on the same wavelength on ethical norms and standards.

\section{e. Ethics programs}

The ethics programs invariably has features such as ethics conduct, training of employees on ethics in a working environment, ways in which employees are able to receive information or even advice on ethical standards, different ways of reporting misconduct in an anonymous manner, disciplinary processes for those employees that do not follow ethical standards that are set and having ethical conduct as part of the employees performance measurement ${ }^{82}$.

\section{f. $\quad$ Ethics officers}

Dodek $^{83}$ asserts that ethics officers are tasked with the responsibility of overseeing the ethics programs in the organisation and implementing ethics initiatives. They also conduct risk and needs assessment activities. Furthermore they are to make sure that the organisation complies with all the regulatory requirements. On the issue of compliance the ethical officers will assess compliance in relation to the employee's ethical performance and the standards on ethics implemented by the organisation.

\footnotetext{
${ }^{80}$ Hassan, Wright \& Yukl (2014).

${ }^{81}$ Nicolaides (2016).

${ }^{82}$ Krisnajava (2018).

${ }^{83}$ Dodek (2018).
} 


\section{g. Effective communication}

Wright, Hassan and Park ${ }^{84}$ argue that management must ensure that there is communication all the time on all ethical issues. The message that is delivered to employees must not be offensive and care should be taken when a decision is made on the kind of information that must be communicated. The information should also be accurate, true and faithfully detailed. The manager delivering the message is required to be fair and not be spiteful or cruel, and biased with, for example, communication .

\section{h. Setting of realistic objectives}

Objectives that are set by the manager should be realistic and not create a situation where the employee might unawares be led to engage in an unethical behaviour $^{85}$. If the expectations are not realistic, that might cause employees to forget about ethical standards which they have to uphold. It is therefore important for managers to be sensitive in the way objectives are set so as to not make employees take short cuts while executing their duties. Ethical norms have to be established and communicated effectively to the entire organisation.

\section{i. $\quad$ Discipline of unethical conduct}

Management needs to take disciplinary action such as misconduct against all members (top management or lower level) who violate ethical norms and standards ${ }^{86}$. Before any disciplinary action can be taken, management must ensure that there has been effective communication on ethical standards of the organisation $^{87}$. Failure to take action on those that do not abide by the set standards will make other employees not believe in the ethical climate and not take the standards that have been set and the rules seriously. Taking action will send a message to all members that the organisation will not tolerate anyone engaging in an unethical behaviour ${ }^{88}$. Establishing an ethical culture is non-negotiable and when investigating corruption, the public service must be able to take effective action at levels matching the corrupt cation perpetrated ${ }^{89}$. All resources stolen must be recovered and would be perpetrators must be clear in their minds that crime does not pay at all.

\footnotetext{
${ }^{84}$ Wright, Hassan \& Park (2016).

${ }^{85}$ Mansouri (2016).

${ }^{86}$ Cohen \& Eimicke (1995).

${ }^{87}$ Yeboah-Assiamah, Asamoah, Bawole \& Buabeng (2015).

${ }^{88}$ Nicolaides (2016).

${ }^{89}$ Heath (2000).
} 


\section{Conclusion}

Ethical conduct is very important for all organisations as it allows them to keep their core values and gives guidance in terms of the relationship between them and their stakeholders as well as other relevant role-players. The public service should have a set of non-negotiable issues and there must be zero tolerance to corruption at the highest political level. All leaders in government need to speak out and act out against corruption. Ethical conduct invariably needs to be binding on all employees within the service as well as with all service providers, agents or any other person linked to the public service whether they are contractors or have any other stake.

It is evident that in institutionalisation of ethics in an organisation requires both implicit and explicit forms. Explicit institutionalisation is a formalisation of clear ethical behaviour which includes policy manuals, codes of ethics, an ethics committee and ethical training materials. Implicit institutionalisation is an indirect expression of ethical behaviour. It involves ethical leadership, evaluation systems, an ethical climate and ethical incentive systems. These two forms are vital and cannot be implemented in isolation in order to realise the desired results. Would be perpetrators of corrupt acts must be made aware of nature of the very severe danger they pose to society through their intended corrupt actions. Corruption is a malady eroding the public service and society and an urgent and ethical communal approach considering the communitarian notion of Ubuntu is required to address the issue. In addition a strong and consistent political will is needed to combating corruption. Ethical leaders need to have a strong ethical dimension since they are also a major role modelling group and have an impact on the public service and all the employees that are part of it. When leaders are modelling a good ethical behaviour, this will likely cascade down to the entire organisation leading to a sustainable society.

\section{References}

Areff, A. (2012). "ANC's cadre deployment drags down public service" in Mail \& Guadian, 12 July, 2012. Available online at http://mg.co.za/article/2012-07-12-anccadre-deployment

Aurand, T.W., Finley, W., Krishnan, V., Sullivanm U.Y., Abresch, J., Bowen, J., Bowen, J., Rackauskas, M., Thomas, R. \& J. Willkomm (2018). "The VW Diesel Scandal: A Case of Corporate Commissioned Greenwashing" in Journal of Organisational Psychology, 18(1):2-32.

Blanche, M. T., Durrheim, K. \& D. Painter (eds.) (2006). Research in Practice: Applied Methods for the Social Sciences, 2 ed. Cape Town: UCT Press

Brown, M. E., Trevino, L. K. \& D.A. Harrison (2005). "Ethical leadership: A social learning perspective for construct development and testing" in Organisational Behavior and Human Decision Processes, 97, 117-134. DOI: 10.1016/j.obhdp.2005. 03.002

Businessstech (April, 2020). Government database to track all public servants accused of fraud and corruption - 22 April 2020, at https://businesstech.co.za/news/techno 
Vol. 6, No. $4 \quad$ Nicolaides \& Manyama: Eradicating Corruption in Public Service ...

logy/391667/new-government-database-to-track-all-public-servants-accused-offraud-and-corruption/

Businesstech (January, 2020). Corruption in South Africa - nobody cares -24 January 2020, at https://businesstech.co.za/news/government/368032/corruption-in-southafrica-nobody-cares/

Carroll, A.B. \& A.K. Buchholtz (2015). Business and society: ethics and stakeholder management. 9th edition. Mason, OH: South-Western College Publishing.

Cohen S. \& W.B. Eimicke (1995). "Ethics and the Public Administrator". The Annuals of the American Academy of Political and Social Science Journal. 537(1):96-108.

Creswell, J.W. (2014). Research Design: Qualitative, Quantitative, and Mixed Methods Approaches. 4 Ed. Sage Publications.

D'Aleo, P. (2018). "Public Administration and Ethics: A Problematic Co-Habitation" in Curentul Juridic, The Juridical Current, Le Courant Juridique, 73(2):21-25.

De Graaf, G. (2007). "Causes of Corruption: Towards A Contextual Theory of Corruption" in Public Administration Quarterly, 31(1/2):39-86.

De Waal, M. (2012). "Cadre deployment, cronyism and paving SA's highway to hell" in Daily Maverick. http://www.dailymaverick.co.za/article

Dodek, A. (2018). "What Lies Ahead for Public Sector Ethics?: Public Sector Ethics" in Canadian Public Administration, 61(3):102-113.

Gberevbie D. E. (2013). "Ethical Issues and Nigeria's Quest for Development" in Rwanda Journal, Series B: Social Sciences, 1(1):21-35.

GCR -The Global Competitiveness Report 2017-2018, World Economic Forum. http:// www3.weforum.org/docs/GCR20172018/05FullReport/TheGlobalCompetitivenessR eport2017\%E2\%80\%932018.pdf

Hassan, S., Wright B. E. \& G. Yukl (2014). "Does Ethical Leadership Matter in Government? Effects on Organisational Commitment, Absenteeism, and Willingness to Report Ethical Problems " in Public Administration Review 74(3):333-343.

Heath, W.H. (2000). "Public Sector Corruption" in Journal of Financial Crime, 7(4): International, 373-375.http://connection.ebscohost.com/c/articles/85635290/businessethics-moral-responsibility-modern-company

Ivanis, M. (2012). Business ethics - moral responsibility of the modern company. Conference Proceedings: International Conference of the Faculty of Economics Sarajevo (ICES):507-525.

Krisnajaya, I.M. (2018). "Institutionalization of Ethical Principles to Overcome Ethical Dilemmas in the Public Sector: in Policy \& Governance Review, 2(1): 1-13.

Leedy, P.D. \& J.E. Ormrod (2015). Practical Research: Planning and Design. 9 ed. Edinburgh Gate: Pearson.

Lokman, A. \& A.T. Talib (2016). "Approaches to Ethics for Public Administrators" in Journal of Administrative Science, 13(2). http:jas.uitm.edu.my

Mafunisa, M.J. (2007). "Corruption and Service Delivery in the Public Service: The case of Limpopo Province" in Journal of Public Administration, 42(3):260-270.

Mansouri, N. (2016). "A Case Study of Volkswagen Unethical Practice in Diesel Emission Test" in International Journal of Science and Engineering Applications, 5(4):211-216.

Manyaka, R.K. \& M.P. Sebola (2013). "Ethical training for effective anti-corruption systems in the South African public service" in Journal of Public Administration, 48(1):75-88.

Mle, T.R. \& S. Maclean (2011). "Ethics, integrity and good governance: the case of South Africa's local sphere of government" in Journal of Public Administration, 46(4):1364-1383. 
Naidoo, R. (2016). Corporate governance - An Essential Guide for South African Companies. 3rd Ed. Durban: LexisNexis.

Nicolaides, A. \& K.C.T. Duho (2019). "Effective Leadership in Organisations: African Ethics and Corruption" in Modern Economy, 10 (7):1713-1743.

Nicolaides, A. (2009). "Business Ethics in Africa" in Journal of Contemporary Management, 6(1):490-501.

Nicolaides, A. (2013). "Fostering the right attitudes to conducting business ethically in South Africa" in Educational Research 4(6):506-512.

Nicolaides, A. (2014). "Utilising Ubuntu to Inform Chief Executive Officer (CEO) Thinking on Corporate Social Responsibility (CSR) and Codes of Ethics in Business" in Journal of Social Sciences 41(1):17-25.

Nicolaides, A. (2016). "Poverty Alleviation and Curbing Corruption in the South African Public Service" in International Journal of Development and Sustainability 5(8):334348.

Nicolaides, A. (2017). "Ethical Practices, Eco-centric Business and Environmental Sustainability" in Journal of Human Ecology 57 (1-2):1-10.

Nicolaides, A. (2019). "Ethical leadership in a morally driven hospitality organisational culture" in African Journal of Hospitality, Tourism and Leisure, 8(5):a50.

Nkyabonaki, J. (2019). "Effectiveness of the Public Service Code of Ethics in Controlling Corrupt Behaviour in The Public Service: Opinion from the Grassroots at Toangoma Ward-Temeke Municipal Council" in Journal of Asian and African Studies 54(8): $1195-1212$.

Plant, J.F. (2018). "Responsibility in Public Administration Ethics" in Public Integrity 20(1):33-45. Doi: 10.1080/10999922.2017.1413927

Public Service Regulations - at http://www.psc.gov.za/conferences/dev-stateconferen ce/Dev\%20State\%20Papers/Chapter\%205\%20Recruitment\%20final\%20Kobus.pdf

Rhodes, C. (2016). "Democratic Business Ethics: Volkswagen's Emissions Scandal and The Disruption of Corporate Sovereignty" in Organisational Studies 37(10):15011518. Doi: $10.1177 / 0170840616641984$

Risk and Compliance Portal (2020). South Africa Corruption Report -May 2019. Available online at https://www.ganintegrity.com/portal/country-profiles/south-afri $\mathrm{ca} /$

Ruhiiga, T.M. (2009). "Costing the impact of corruption on service delivery in South Africa: An exploratory overview" in Journal of Public Administration, 44(4):10901101 .

Sayeed, C.N.M. (2016). "Beyond Codes of Conduct Towards a Public Service Ethos in South Africa" in African Journal of Public Affairs, 9(3):39-50.

Sebola, M.P. (2018). "The South African Public Service and the Ethical Problematiques: The Discipline and Practice Talking Different Tongues" in African Journals of Public Affairs, 10(4):57-67.

Shava, E. (2016). "Black Economic Empowerment in South Africa: Challenges and Prospects" in Journal of Economics and Behavioral Studies, 8:161-170.

Sims, R.R. (2017). A Contemporary Look at business Ethics. Charlotte NC: Information Age Publishing business ethics.

Soliman, H. \& S. Cable (2011). "Sinking under the weight of corruption: Neoliberal reform, political accountability and justice" in Current Sociology, 59(6):735-753

South African Government (2004). Prevention and Combating of Corrupt Activities Act 12 of 2004. Available online at https://www.gov.za/documents/prevention-andcombating-corrupt-activities-act-0 
Vol. 6, No. $4 \quad$ Nicolaides \& Manyama: Eradicating Corruption in Public Service ...

Svensson, G. (2004). "Codes of Ethics Best Practice in the Swedish Public Sector: A PUBSEC-scale" in International Journal of Public Sector Management, 17(2):178195.

Thornhill, C. (2012). "Improving local government transformation in South Africa" in Administratio Publica, 20(3):128-143.

Treasury.gov.za (1999). Public Finance Management Amendment Act, No. 29 of 1999, Available at http://www.treasury.gov.za/legislation/pfma/act.pdf

Wright, B.E., Hassan, S. \& J. Park (2016). "Does a Public Service Ethic Encourage Ethical Behaviour? Public Service Motivation, Ethical Leadership and the Willingness to Report Ethical Problems" in Public Administration, 94(3):647-663

Yeboah-Assiamah, E., Asamoah, K., Bawole J. N. \& T. Buabeng (2016). "Public sector leadership-subordinate ethical diffusion conundrum: perspectives from developing African countries" in Journal of Public Affairs, 16(4):320-330. 